\title{
Simulasi Proses Torefaksi Sampah Sistem Kontinu Menggunakan Software Aspen Plus
}

\author{
Amrul, Dedi Triyadi, Indra M. Gandidi \\ Jurusan Teknik Mesin Fakultas Teknik Universitas Lampung \\ Jl. Prof. Soemantri Brojonegoro No.1 Gedung Meneng \\ Universitas Lampung, Kedaton, Bandar Lampung 35145 \\ E-mail: amrul@eng.unila.ac.id
}

\begin{abstract}
The heating value of solid fuels obtained from torrefied MSW reaches 6,000 kcal/kg so that it has the potential to replace coal. The challenge faced today is how to develop a continuous reactor system to get solid fuel from torrefied MSW. The objective of this study is to simulate torrefaction process using ASPEN ${ }^{T M}$ software on a continuous system with a tubular reactor. MSW feed capacity of $5 \mathrm{~kg} / \mathrm{hr}$ with variation of moisture content about 30-80\%. The simulation system consists of a drying reactor (Rstoic), a reactor of torefaction (RYield), a separator and a splitsparator. The drying process retained at temperature $100^{\circ} \mathrm{C}$ and torefaction temperature at $275^{\circ} \mathrm{C}$, occurring continuously on the tubular reactor. The simulation results show that the mosture content content of MSW has significant effect on the energy requirement in the drying and torefaction process. The energy required for torefaction increased by about $1.6 \mathrm{~kW}$ to $3.4 \mathrm{~kW}$ in a 30-80\% moisture content variation, while solid fuel production decreased by about $2.1 \mathrm{~kg} / \mathrm{hr}$ to $0.6 \mathrm{~kg} / \mathrm{hr}$
\end{abstract}

Keywords:

\begin{abstract}
Abstrak
Nilai kalor bahan bakar padat yang diperoleh dari produk sampah torefaksi mencapai $6.000 \mathrm{kcal} / \mathrm{kg}$ sehingga berpotensi menggantikan batu bara. Tantangan yang dihadapi saat ini adalah bagaimana mengembangkan sistem reaktor kontinu untuk mendapatkan bahan bakar padat dari produk torefaksi sampah. Tujuan penelitian ini adalah melakukan simulasi menggunakan perangkat lunak ASPEN ${ }^{T M}$ untuk memodelkan proses torefaksi sampah pada sistem kontinu dengan reaktor tubular. Kapasitas umpan sampah sebesar $5 \mathrm{~kg} / \mathrm{jam}$ dengan variasi kandungan air umpan sampah 30-80\%. Sistem simulasi terdiri dari sebuah reaktor pengering (Rstoic), reaktor torefaksi (RYield), separator dan splitsparator. Proses pengreingan ditahan pada temperatur $100{ }^{\circ} \mathrm{C}$ dan torefaksi pada $275^{\circ} \mathrm{C}$, terjadi secara kontinu pada reaktor tubular. Hasil simulasi menunjukkan kandungan air sampah umpan memberikan pengaruh terhadap kebutuhan energi pada proses pengeringan dan proses torefaksi sampah. Kebutuhan energi torefaksi meningkat sekitar 1,6 kW-3,4 kW pada variasi kandungan air sampah umpan 30-80\%, sedangkan produksi bahan bakar padat berkurang sekitar 2,1 kg/jam menjadi 0,6 kg/jam.
\end{abstract}

Kata kunci:

\section{PENDAHULUAN}

Sampah adalah komponen heterogen dengan kandungan air dan densitas energi yang rendah. Selama ini, sampah dikenal sebagai salah satu sumber masalah khususnya di kota-kota besar di Indonesia, yang memiliki potensi sebagai sumber bahan bakar alternatif yang potensial unutk dikembangkan. Nilai kalor yang dapat dibangkitkan dari sampah kota sekitar 25,2 MJ/kg[1]. Namun, dalam aplikasi pengolahan sampah itu sendiri memiliki berbagai kendala, baik itu kendala teknis ataupun kendala non teknis.

Melihat keadaan tersebut diperlukan suatu metode yang tepat untuk dapat mengelola sampah dan memanfaatkan sampah menjadi salah satu sumber energi alternatif. Salah satu teknologi yang dapat digunakan untuk mengkonversi sampah menjadi bahan bakar padat adalah torefaksi. Torefaksi adalah proses perlakuan panas pada temperatur $200-300^{\circ} \mathrm{C}$ pada tekanan atmosfer tanpa adanya oksigen pada proses. Torefaksi pada sampah dapat menghasilkan bahan bakar padat setara batu bara Sub-bituminous[2].

Untuk dapat melakukan pengolahan dan pemanfaatan sampah yang lebih efektif, diperlukan sebuah sistem pengolahan kontinu dengan skala industri yang diharapkan dapat mengurangi sampah dalam jumlah besar serta mampu menghasilkan bahan bakar dari sampah dengan laju produksi yang lebih tinggi dari sistem batch. Berkaitan dengan hal tersebut, dibutuhkan suatu penelitian dan eksperimen-eksperimen lebih lanjut untuk mendapatkan parameter terkait pengembangan sistem torefaksi sampah kontinyu.

Proses pengembangan sistem torefaksi sampah kontinu tentu mebutuhkan penelitian dengan biaya besar dan waktu yang cukup lama. Meminimalisir dari keadaan tersebut, digunakan sebuah simulator perangkat lunak yang diharapkan mampu 
mengurangi biaya dan memberikan efisiensi waktu terhadap proses pengembangan sistem torefaksi sampah kontinu. Perangkat lunak yang digunakan dalam mensimulasikan proses torefaksi sampah kontinu adalah menggunakan Aspen Plus.

Simulasi dirancang pada proses torefaksi sampah sistem kontinu skala lab, untuk mendukung penelitian pada proses torefaksi sampah sistem kontinu skala industri dengan umpan sampah awal $5 \mathrm{~kg} / \mathrm{jam}$ dengan temperatur proses torefaksi $275 \mathrm{oC}$. Pemvariasian kandungan air sampah umpan diberikan dengan variasi $30-80 \%$ sebagai salah satu parameter untuk mendapatkan jumlah rendemen produk padatan dan kebutuhan energi yang dibutuhkan pada proses torefaksi sampah sistem kontinu.

Sampah dapat dibagi menjadi 4 (empat) kategori : sampah kota, limbah pertanian, limbah peternakan dan limbah kayu[3]. Sampah kota adalah campuran dari limbah, yang terutama dari perumahan dan komersil yang terdiri dari sisa makanan, limbah taman, produk kertas, plastik dan kayu[4]. Biomassa menjadi salah satu komponen utama penyusun dari sampah.

Torefaksi merupakan proses perlakuan panas pada temperatur sekitar $200-320^{\circ} \mathrm{C}$ pada tekanan atmosfer tanpa kehadiran oksigen. Produk utama torefaksi terdiri dari padatan, gas dan cairan. Torefaksi pada biomasa berhasil memperbaiki karakteristik biomassa sebagai bahan bakar padat, yang di tandai dengan meningkatnya nilai kalor, densitas energi yang tinggi, kandungan air yang rendah, dan hidrofobia[5]. Proses torefaksi adalah proses termal yang dilaukan dengan pemanas pada kondisi menengah.

Tahapan pemanasan pada proses torefaksi biomassa memiliki hubungan terkait dengan perubahan massa, suhu dan konsumsi energi biomassa dalam proses torefaksi.Tahapan pemanasan pada torefaksi dibagi menjadi 4 (empat) tahapan pemanasan, predrying, drying, postdrying dan torrefaction[6]. Selain dari pada tahap pemanasan, terdapat beberapa parameter yang mempengaruhi dari proses torefaksi. Parameterparameter yang dimaksud adalah temperatur, waktu tinggal, jenis biomassa dan ukuran partikel.

Sedangkan perangkat lunak Aspen plus merupakan suatu perangkat lunak simulasi yang menggunakan ubungan besaran fisika, seperti neraca massa, neraca panas, kesetimbangan termodinamika dan persamaan kecepatan yang dapat digunakan untuk memprediksi performa suatu proses, seperti sifat aliran dan kondisi operasi dari suatu alat ukur[7].

\section{METODOLOGI PENELITIAN}

Subtansi penelitian yang akan dilakukan adalah membuat simulasi torefaksi sampah sistem kontinu menggunakan perangkat lunak Aspen Plus.

\section{Prosedur penelitian}

Langkah awal adalah mengumpulkan data ultimate dan proximate dari sampah yang diambil dari data skunder. Data analisis ultimate dan proximate sampah digunakan sebagai umpan pada model simulasi.

Tabel 1 Data Ultimate dan Proximate sampah

\begin{tabular}{|c|c|c|c|c|c|c|c|c|}
\hline \multicolumn{4}{|c|}{ Data Komposisi Komponen Sampah Kota } \\
\hline \multicolumn{3}{|c|}{$\begin{array}{c}\text { Analisis Proksimat } \\
(\%) a d b\end{array}$} & \multicolumn{5}{c|}{$\begin{array}{c}\text { Analisis Ultimat } \\
(\%)\end{array}$} \\
\hline MC & VM & FC & Abu & C & H & N & S & O \\
\hline 11,51 & 70,97 & 11,14 & 6,38 & 47,59 & 6,85 & 1,18 & 0,19 & 37,83 \\
\hline
\end{tabular}

Langkah selanjutnya adalah melakukan pemodelan simulasi dari proses torefaksi sampah sistem kontinu. Model simulasi torefaksi sampah dirancang dengan kapasitas umpan sampah 5 $\mathrm{kg} / \mathrm{jam}$ dan temperatur torefaksi $275^{\circ} \mathrm{C}$ menggunakan reaktor tubular dengan asumsi model dalam keadaan steady state dan kondisi isothermal. Model simulasi dilakukan pada perangkat lunak Aspen plus yang terdiri dari unit blok Rstoic, Flash2, Heater, Ryiel dan Ssplit.

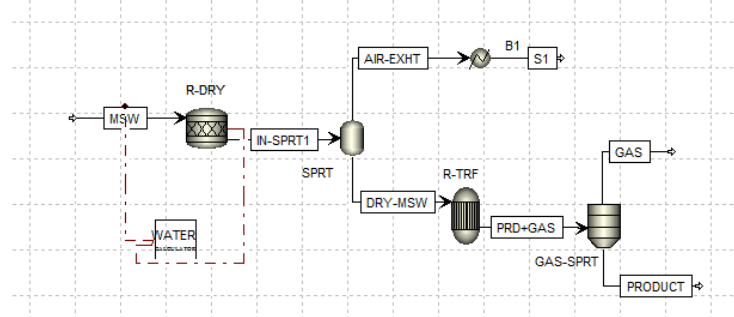

Gambar 1 Skema simulasi torefaksi sampah kontinu Aspen plus

Metode pengambiilan data dilakukan dengan melakukan running pada model simulasi Aspen plus. Pemvariasian kandungan air sampah umpan dilakukan pada keadaan $30-80 \%$ dengan selang $5 \%$ untuk mendapatkan pengaruh kadar air samapah umpan terhadap rendemen produk dan energi proses yang dibutuhkan pada proses torefaksi sampah sistem kontinu.

\section{HASIL DAN PEMBAHASAN}

Hasil simulasi proses torefaksi sampah yang telah dilakukan ditampilkan pada Tabel 2. 
Tabel 2 Data hasil simulasi

\begin{tabular}{|c|c|c|c|c|}
\hline \multirow[t]{2}{*}{$\begin{array}{c}\text { MC } \\
\%\end{array}$} & \multicolumn{2}{|c|}{$\begin{array}{c}\text { Kebutuhan } \\
\text { Panas (W) }\end{array}$} & \multicolumn{2}{|c|}{ Produk (kg/jam) } \\
\hline & $\begin{array}{l}\text { Penge } \\
\text { ringan }\end{array}$ & $\begin{array}{l}\text { Torefa } \\
\text { ksi }\end{array}$ & Gas & Padat \\
\hline 30 & 248 & 972 & 3,025 & 1,975 \\
\hline 35 & 262 & 1.160 & 3,166 & 1,834 \\
\hline 40 & 277 & 1.349 & 3,307 & 1,693 \\
\hline 45 & 291 & 1.537 & 3,448 & 1,552 \\
\hline 50 & 305 & 1.725 & 3,589 & 1,411 \\
\hline 55 & 320 & 1.914 & 3,730 & 1,270 \\
\hline 60 & 334 & 2.101 & 3,871 & 1,129 \\
\hline 65 & 348 & 2.289 & 4,012 & 0,988 \\
\hline 70 & 363 & 2.478 & 4,154 & 0,846 \\
\hline 75 & 377 & 2.666 & 4,294 & 0,706 \\
\hline 80 & 392 & 2.855 & 4,436 & 0,564 \\
\hline
\end{tabular}

\section{Analisis produk torefaksi}

Peningkatan dan variasi kandungan air pada sampah umpan sangat mempengarui dari produk torefaksi, seperti ditunjukkan oleh Gambar 2. Pemvariasian kandungan air sampah umpan pada model simulasi torefaksi sampah sistem kontinu menunjukkan bahwa, kandungan air pada sampah umpan tertinggi yaitu $80 \%$ menghasilkan produksi gas tertinggi yaitu $4,436 \mathrm{~kg} / \mathrm{jam}$ dengan produksi bahan bakar padat terendah yaitu $0,564 \mathrm{~kg} / \mathrm{jam}$. Sedangkan untuk mendapatkan produksi bahan bakar padat tertinggi $1,975 \mathrm{~kg} / \mathrm{jam}$ dapat dicapai pada kondisi air sampah umpan terendah yaitu $30 \%$. Hal tersebut menunjukkan bahwa kadar air pada sampah umpan sangat berperan terhadap rendemen produk yang didapatkan dari simulasi proses torefaksi sampah sistem kontinu.

\section{Analisis kebutuhan panas}

Analisis kebutuhan energi panas proses torefaksi dapat diketahui dari jumlah energi pengeringan dan torefaksi. Pemvariasian kandungan air pada sampah umpan digunakan untuk mengetahui jumlah energi pada torefaksi.

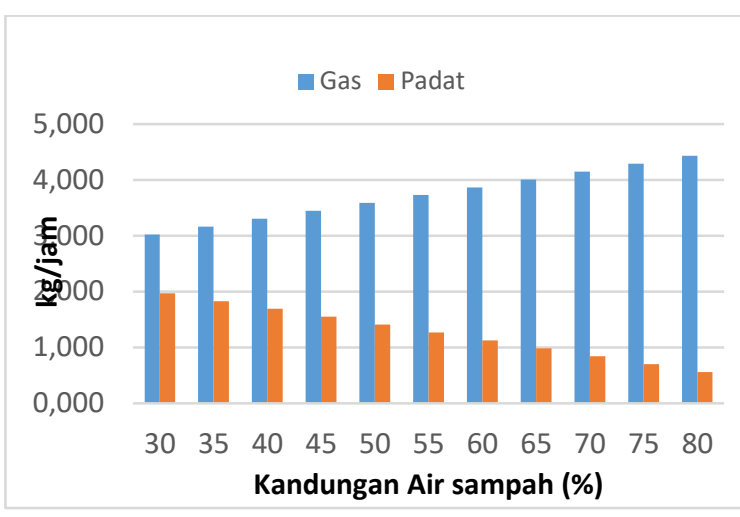

Gambar 2 Pengaruh kadar air terhadap produk torefaksi

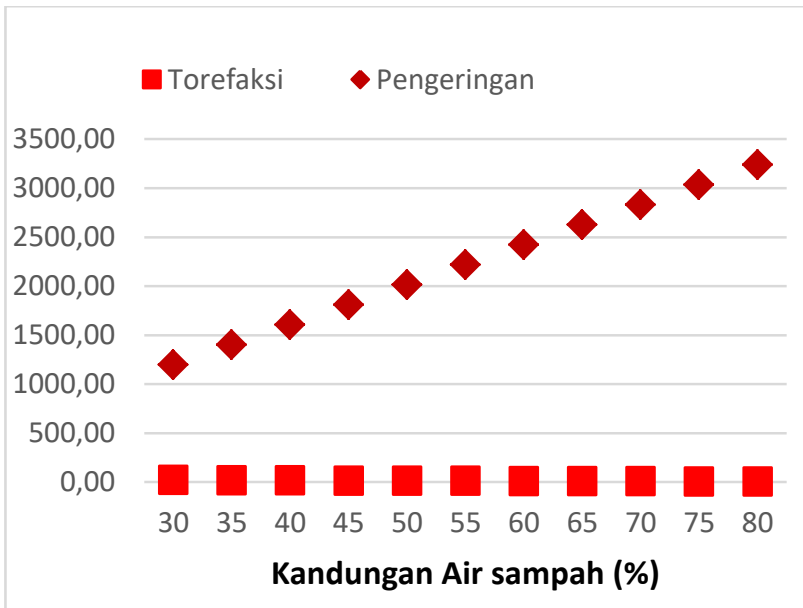

Gambar 3 Keseimbangan panas proses.

Kebutuhan energi pada proses pengeringan meningkat $1,197 \mathrm{~kW}-3,240 \mathrm{~kW}$ sebanding dengan peningkatan kandungan air umpan pada sampah, seperti ditunjukkan oeh Gambar 3. Hal tersebut disebabkan oleh jumlah sampah kering yang mengalami proses torefaksi terus berkurang. Total kebutuhan energi panas tertinggi dan terendah yang dibutuhkan selama proses didapkan sebesar 1,220 $\mathrm{kW}$ dan 3,240 kW pada kondisi air umpan sampah $30 \%$ dan $80 \%$.

Dengan asumsi nilai kalor bahan bakar padat hasil torefaksi sebesar $25,2 \mathrm{MJ} / \mathrm{kg}^{[1]}$ didapatkan perbandingan antara kebutuhan energi dan energi yang dapat dihasilkan dari bahan bakar padat seperti dilihat pada Gambar 4. 


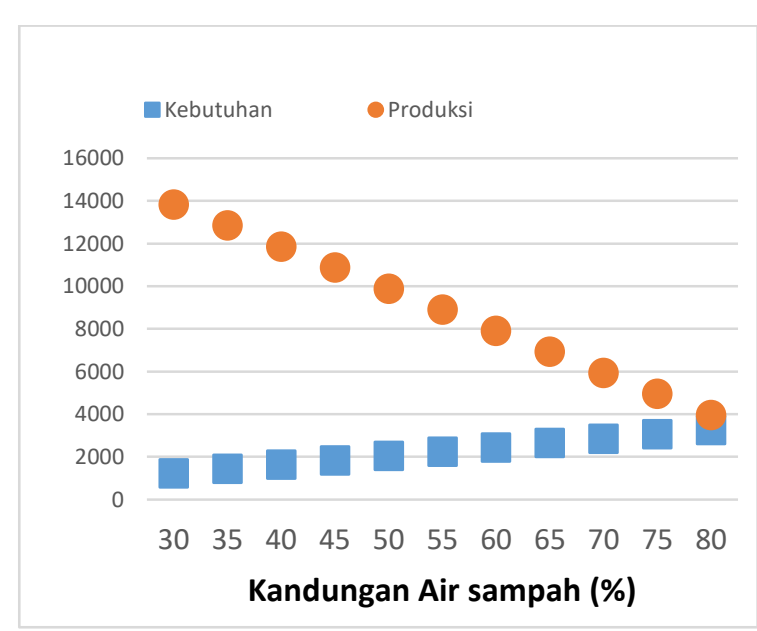

Gambar 4 Perbandingan kebutuhan dan produksi energi

Dari asumsi yang diberkan didapatkan produksi energi tertinggi yang dapat dibangkitkan dari produk torefaksi sampah kontinu adalah 13,8 $\mathrm{kW}$ dengan kebutuhan panas proses sebesar 1,353 $\mathrm{kW}$ pada variasi air sampah umpan $30 \%$. Sedangkan produksi energi terendah yang didapatkan adalah $3,938 \mathrm{~kW}$ dengan kebutuhan panas proses $3,24 \mathrm{~kW}$ pada kondisi air sampah umpan $80 \%$.

\section{KESIMPULAN}

Dari simulasi model dan pembahasan yang sudah dilakukan pada Bab sebelumnya berkaitan dengan proses torefaksi sampah sistem kontinu, dapat disimpulkan bahwa:

1. Estimasi produksi bahan bakar padat atau rendemen tertinggi dari model simulsi proses torefaksi sampah sistem kontinu adalah sebesar $1,975 \mathrm{~kg} / \mathrm{jam}$ dan terendah $0,564 \mathrm{~kg} / \mathrm{jam}$ dari sampah umpan dengan kondisi kandungan air $30 \%$ dan $80 \%$.

2. Kebutuhan panas total pada simulasi proses torefaksi sistem kontinu tertinggi didapatkan sebesar 3.240 watt pada kondisi kandungan air sampah umpan $80 \%$, serta kebutuhan panas terendah sebesar 1.220 watt pada kondisi kandungan air sampah umpan $30 \%$.

\section{UCAPAN TERIMA KASIH}

Penulis mengucapkan terima kasih kepada Kementerian Riset Teknologi dan Pendidikan Tinggi Republik Indonesia serta LPPM Universitas Lampung yang telah mendanai penelitian ini untuk tahun anggaran 2017.

\section{DAFTAR PUSTAKA}

[1] Pasek A. D., Hardianto T., Ardiansyah W. dan Suwono A. 2007. "Laporan Akhir Studi Kelayakan Pembangkit Listrik dengan Bahan Bakar Sampah di Kota Bandung”. LPPM ITB, Bandung.

[2] Amrul, Hardianto T., Suwono A. dan A. D. Pasek.

2010. "Upgrading Fuel to Subituminous Coal Grade by Torefaction Process", Proceeding of Regional Conference on Mechanical and Aerospace Technology: 9-10 Februari 2010. Bali.

[3] Klass D. L. 1998. "Biomass for Renewable Energy", Fuels, and Chemicals. Academic Pres, pp. 30, 276-277, 233, 239.

[4] Dixon Neil, D. Russel dan V. Jones. 2004. "Engineering Properties of Municipal Solid Waste". Department of Civil and Building Engineering, Loughborough University, Leicestershire. UK.

[5] Chen W.H. dan Kuo P.C. 2011. "Torrefaction and Co-Torrefaction Characterization of Hemisellulose, Cellulose and Lignin as Well as Torrefaction of Some Basic Constituents in Biomass".

[6] Basu Pabir. 2013. Biomass Gasification, Pyrolysis, and Torrefaction: Practical Design and Theory, Second Edition. Elsevier, Oxford, UK.

[7] Scott Folger H. dan Gurmen Nihat M. 2002. Aspen Plus Workshop for Reaction Engineering and Design. Department of Chemical Engineering, The University of Michigan, Ann arbor, MI 